\section{Sida e infecciones
de transmisión sexual
en las Américas ${ }^{1}$ \\ Sida e infecciones
de transmisión sexual
en las Américas \\ Sida e infecciones
de transmisión sexual
en las Américas}

1 Se basa en: Organización Panamericana de la Salud, División de Prevención y Control de Enfermedades, Programa Regional de SIDA/ ETS. Síndrome de Inmunodeficiencia Adquirida (sida) en las Américas. Washington, D.C.: OPS; 1999.

2 Se refiere exclusivamente a Estados Unidos de América y Canadá. Aunque México también forma parte de América del Norte, sus datos se incluyen en el rubro de América Latina.

\section{Evolución de las epidemias en la Región: retos y oportunidades}

Pese a los esfuerzos sustanciales desplegados en el último decenio, las epidemias de la infección por el VIH/sida y de las infecciones de transmisión sexual (ITS) siguen representando un grave problema de salud pública en la Región de las Américas. La Organización Panamericana de la Salud (OPS) calcula que 1,6 millones de personas viven con la infección por el VIH en América Latina y el Caribe, y cerca de un millón en América del Norte. ${ }^{2}$ En 1998, las tasas de prevalencia en adultos - es decir, la proporción de personas de 15 a 49 años de edad que tienen la infección por el $\mathrm{VIH} /$ sida - se estimaban en alrededor de 1 en 200 en América del Norte y América Latina $(0,56 \%$ y $0,57 \%$, respectivamente) y de 1 en 50 en el Caribe $(1,96 \%)$. Estas tasas de prevalencia son mayores que las de otras regiones, como Europa occidental, el Pacífico occidental y Australia y Nueva Zelandia. Las tasas del Caribe solo son superadas por las de África subsahariana, que es la región más afectada del mundo.

En este momento, la pandemia de infección por el VIH/sida consta de dos tipos de epidemias diferentes: una se concentra en individuos cuyas prácticas les confieren un alto riesgo de infección; la otra se encuentra generalizada entre la población. Hay gran variedad de vías de transmisión y de grupos de población afectados, de tal modo que las fuerzas impulsoras de la epidemia de infección por el VIH/sida varían entre distintos países y dentro de un mismo país. Un elemento común a ambos tipos de epidemias es la elevada prevalencia de la infección por el VIH en los grupos social y económicamente marginados, la que acentúa las faltas de equidad en el acceso a la asistencia sanitaria.

La infección por el VIH/sida ha afectado desproporcionadamente a los hombres que tienen relaciones homosexuales sin protección y a los usuarios de drogas inyectables. Sin embargo, en algunos lugares hay pruebas fehacientes de una mayor propa gación en personas pobres y analfabetas. Además, la transmisión heterosexual muestra también un incremento progresivo, como lo indican las tasas ascendentes en mujeres y lactantes.

Los principales factores que definen la gravedad de las epidemias y que despiertan la inquie- 
tud de los expertos en salud pública son los siguientes:

- La presencia de obstáculos sociales y culturales para modificar los comportamientos de alto riesgo, especialmente en los grupos más vulnerables;

- el desplazamiento de la epidemia de infección por el VIH a las poblaciones más jóvenes;

- el aumento de la prevalencia de ITS, en especial de la infección por el VIH, en grupos con acceso restringido o limitado a la educación en salud y a los servicios de asistencia sanitaria;

- la continua vulnerabilidad biológica, social y económica de las mujeres, así como la falta de métodos de protección eficaces (microbicidas, barreras físicas y químicas) que la población femenina pueda utilizar de manera fácil y sistemática;

- el número cada vez mayor de casos de transmisión de la infección de madre a hijo;

- la presencia confirmada de diversos subtipos patógenos de VIH-1 en la Región;

- la aparición de farmacorresistencia en los agentes patógenos de transmisión sexual, incluido el VIH.

Tipología de las epidemias de infección por el VIH/sida y de ITS en la Región. Como ya se señaló, la epidemia de infección por el VIH/sida todavía afecta principalmente a los hombres homosexuales. No obstante, la transmisión heterosexual está cobrando importancia en la Región, a juzgar por el aumento de las tasas de infección en las mujeres. De los adultos positivos al VIH, 20\% en América del Norte y América Latina y más de 30\% en el Caribe son mujeres. Simultáneamente se han registrado mayores tasas de infección por el VIH/sida en los lactantes en casi todos los Estados Miembros, fenómeno que refleja el aumento de la transmisión del VIH de madre a hijo. En los países de la Región donde hay poca transmisión o donde la epidemia se concentra en ciertos grupos, la prevalencia de infección por el VIH en las mujeres embarazadas es menor de $1 \%$. Sin embargo, en los países con epidemia generalizada - donde la infección por el VIH se ha propagado a la población en general- la prevalencia en las mujeres embarazadas es mayor de $5 \%$. Esto sucede en las Bahamas, Guyana y Haití, así como en algunas zonas urbanas del Brasil y en la costa caribeña de Honduras.

Hasta hace poco, solo un subtipo del VIH-1 (B) se había identificado como agente causal de la epidemia de sida en la Región de las Américas; sin embargo, algunos estudios han demostrado la introducción de otros subtipos en el continente. Este hecho puede repercutir en la dinámica de la transmisión, la patogenia del sida y la obtención de una vacuna eficaz. Es más, la introducción de tratamientos antirretrovíricos ha llevado a la aparición de cepas víricas resistentes que quizá ya estén circulando en la Región.

Para planificar estrategias eficaces de prevención y control de la infección por el VIH, la vigilancia epidemiológica no debe limitarse a la notificación de los casos de sida. La vigilancia centinela, los estudios de seroprevalencia de la infección por el $\mathrm{VIH} /$ sida, la vigilancia de los comportamientos riesgosos y la genética molecular aplicada a la vigilancia del virus son herramientas epidemiológicas que necesitan incorporarse en un método de "vigilancia de segunda generación" más actualizado.

Infecciones de transmisión sexual. Las ITS no solo aumentan las probabilidades de contraer la infección por el VIH, sino que son en sí mismas un grave problema de salud. Aunque en la Región de las Américas no se conoce el verdadero número de casos sintomáticos de ITS (sin contar los relacionados con el VIH), se calcula una cifra de incidencia anual de alrededor de 50 millones de ITS tratables. Algunos estudios indican que cada año aproximadamente $20 \%$ de los adultos jóvenes y adolescentes sexualmente activos contraen una infección de transmisión sexual. Estas cifras pueden servir como indicadoras de la frecuencia con que se producen relaciones sexuales sin protección, a pesar de los esfuerzos para informar al público sobre este factor de riesgo conductual y sobre la amenaza de infección por el VIH. Hay una gran necesidad de fortalecer la capacidad local para evaluar mejor la situación de las ITS, los comportamientos de riesgo asociados con su transmisión y los factores que obstaculizan su prevención y control.

\section{Respuestas y retos actuales}

El reto de mejorar la vigilancia. La notificación de la infección por el VIH y de los casos de sida permite comprender mejor la dinámica actual de las epidemias, pero conlleva la necesidad de respetar los derechos humanos, garantizar la confidencialidad y evitar el uso indebido de la información (que podría utilizarse para limitar el acceso a la educación, al empleo, a los servicios, a la vivienda o a cualquier otro derecho individual). La vigilancia de la infección por el VIH debe planificarse cuidadosamente para que tenga la debida calidad técnica y cumpla con los principios éticos.

La vigilancia basada en la genética molecular está vinculada estrechamente con la vigilancia de la infección por el VIH y está regida por las mismas 
exigencias técnicas y éticas para la obtención de muestras de los individuos para someterlas a pruebas de detección. En colaboración con la Oficina de Investigación Naval de los Estados Unidos, varios países (incluidos Argentina, Bolivia, Ecuador, Perú y Uruguay) pronto emprenderán un estudio multicéntrico para tipificar las características genéticas del VIH que circula en su territorio. Además, en la reunión de redes de epidemiología de América Latina y el Caribe, celebrada en Cuernavaca, México, en abril de 1999 con la participación de expertos de los países y representantes de las instituciones, se lograron grandes adelantos con respecto a un enfoque multicéntrico (tanto interinstitucional como internacional) de la vigilancia de segunda generación de la infección por el VIH/sida y las ITS.

La prestación de servicios de orientación y de pruebas detectoras. Las políticas de salud pública deben destacar el valor del acceso voluntario a las pruebas detectoras del VIH y el valor agregado de la orientación, que ofrece la oportunidad de proporcionar apoyo a la persona infectada por el VIH y de ayudarla a cumplir con su tratamiento. La orientación también representa la mejor oportunidad de persuadir a la persona para que contribuya a detener la propagación del VIH, adoptando comportamientos menos riesgosos y procurando que su pareja también tenga acceso a los servicios de orientación y pruebas. Aunque el resultado de las pruebas sea negativo, una buena orientación puede ayudar a una persona a trazar planes con respecto a su salud sexual futura.

La orientación debe ser algo más que el mero suministro de información objetiva. Cuando se proporciona adecuadamente, ayuda al individuo con una prueba positiva a hacer frente al resultado y a formular un plan de vida adecuado. Por este motivo, la orientación no es solo una estrategia de prevención; es el primer paso en la prestación de atención integral a las personas que viven con la infección por el VIH. Con este fin, la secretaría de la OPS ha producido y diseminado en sus Estados Miembros tres manuales de adiestramiento y consulta. ${ }^{3}$

La necesidad de modelos de atención de la infección por el VIH/sida. Si bien la OPS reconoce los beneficios de los medicamentos antirretrovíricos $(A R V)$ en el manejo de la infección por el VIH y en

\footnotetext{
3 Principios y prácticas del aconsejamiento sobre el VIH/sida; Guía para la atención domiciliaria de personas que viven con VIH/sida, y Normas para el manejo de las mujeres con infección por el VIH/sida. Este último manual, cuya versión en castellano está en preparación, abarca la prevención de la transmisión de madre a hijo.
}

la prevención de su transmisión por vía perinatal, es necesario que los Estados Miembros los consideren como un componente más de los servicios de atención continua e integral, que deben incluir otras intervenciones más básicas y asequibles: prevención, educación, orientación, acceso a las pruebas de infección por el VIH, tratamiento profiláctico de las infecciones oportunistas, tratamiento de las ITS, intervenciones nutricionales, atención domiciliaria, manejo del estrés y apoyo emocional y social.

En dos reuniones de consulta regionales (noviembre de 1998 y mayo de 1999) se propusieron los elementos fundamentales para mejorar la calidad y la prestación de los servicios asistenciales relacionados con la infección por el VIH: a) integración de cuidados domiciliarios y respuestas comunitarias con los servicios de salud en sus distintos niveles de atención; b) definición de las intervenciones esenciales que deben realizarse en cada instancia, con atención a los recursos disponibles; c) definición de indicadores cuantitativos y cualitativos de la calidad de los servicios, y d) incorporación de elementos de prevención secundaria y terciaria en los estándares de atención (nutrición, higiene, profilaxis de infecciones oportunistas, ejercicio y relajación), más allá de la mera provisión de tratamiento sintomático o antirretrovírico. Estos elementos fundamentales serán los principios orientadores para concebir servicios integrales y asequibles para hombres, mujeres y niños de las Américas que, cada vez en mayor número, viven con la infección por el VIH. De igual manera, la OPS sigue en busca de mecanismos financieros, legales, técnicos y administrativos para reducir los costos de los ARV mediante el establecimiento de un fondo rotatorio.

Prevención y control de las infecciones de transmisión sexual. En 1998, una encuesta reveló que los programas de ITS se habían reducido considerablemente en la mayoría de los países de la Región, mientras sus recursos se destinaban a hacer frente a la epidemia de infección por el VIH/sida. Sin embargo, la comprobación científica de que el manejo adecuado de las ITS disminuye en 50\% la transmisión sexual del VIH ha venido a reavivar el interés por prevenir las ITS. La OPS y la Organización Mundial de la Salud (OMS) han promovido el manejo sindrómico de las ITS; como resultado, a fines de 1998 todos los países de la Región habían tenido acceso a los materiales de adiestramiento más recientes y adecuados. El adiestramiento nacional se ha realizado a la fecha en siete países. Además, las normas de vigilancia de segunda generación de las ITS se modificaron en la reunión de redes de epidemiología realizada en abril de 1999 y servirán 
como herramienta práctica para mejorar la vigilancia de ese tipo de infecciones en las Américas.

Como consecuencia de la necesidad de frenar la transmisión perinatal del VIH, el antiguo y a menudo descuidado problema de la sífilis congénita se está abordando con mayor interés en más países (por ejemplo, Bolivia, Brasil, Cuba, México, Panamá, Uruguay). Además, la OPS ha elaborado protocolos para la prevención y el tratamiento de ITS en mujeres embarazadas.

Después de la iniciativa PACETS (estrategia integral para la prevención, atención y control de las enfermedades de transmisión sexual) de la OMS, se está organizando en las Américas un grupo de estudio regional sobre ITS con aportaciones de expertos de los países, otros organismos internacionales y los programas pertinentes de la OPS. El objetivo es diseñar métodos prácticos para la movilización de recursos y el fortalecimiento técnico de las actividades nacionales de control de las ITS.

Reducción de la transmisión del VIH de madre a hijo. Paralelo al aumento de la transmisión heterosexual del VIH en las Américas se ha observado un aumento de la transmisión de madre a hijo. Hasta septiembre de 1998 se habían notificado 6323 casos de este tipo en la Región.

Varias estrategias preventivas pueden reducir el riesgo de que una madre transmita el VIH a su hijo: manejo durante el parto; cesárea electiva o lavado vaginal en combinación con medicamentos antirretrovíricos; y alimentación de reemplazo para lactantes en riesgo.

Estudios efectuados en Tailandia han revelado que un tratamiento breve con zidovudina (AZT) administrada al final del embarazo y durante el parto reduce a la mitad (51\%) la tasa de transmisión del VIH y puede usarse sin riesgo en países en desarrollo. Comparado con el protocolo ACTG076 elaborado en 1994, el régimen con AZT es mucho más corto durante el embarazo (en general se administra solo en las últimas 4 semanas) y consiste en una dosis oral para la madre (sin ninguna dosis intravenosa durante el parto y sin ninguna dosis para el neonato). Este tratamiento cuesta en total entre US\$ 80 y US $\$ 100$, en comparación con los US\$ 1000 que cuesta el protocolo ACTG076.

Un estudio más reciente del Programa Conjunto de las Naciones Unidas sobre el VIH/SIDA (ONUSIDA), el ensayo PETRA (por PErinatal TRAnsmission) que se llevó a cabo en cinco localidades del África, ha revelado que un tratamiento aun más breve, administrado durante el trabajo de parto y seguido de una semana de farmacoterapia combinada (AZT y 3TC) tanto para la madre como para el neonato, redujo la tasa de transmisión de madre a hijo en $37 \%$. En este régimen, las mujeres tomaron los dos medicamentos en comprimidos dos veces al día y el lactante los tomó en forma de jarabe durante una semana. Se calcula que esta farmacoterapia cuesta una quinta parte de lo que cuesta el régimen estudiado en Tailandia, es decir, entre US\$ 16 y US\$ 20.

Un gran estudio realizado en más de 8500 binomios de madres e hijos mostró que las mujeres embarazadas infectadas por el VIH pueden reducir el riesgo de transmitir el virus a sus hijos en aproximadamente $50 \%$ si se someten a cesárea electiva antes de entrar en trabajo de parto y antes de la ruptura de las membranas.

En este momento Argentina, Bahamas, Barbados, Brasil, Chile, Cuba, Uruguay y otros países están destinando abundantes recursos a prevenir la transmisión del VIH de madre a hijo.

Mantenimiento de un suministro inocuo de sangre. El redoblamiento de los esfuerzos que se inició gracias al advenimiento de las pruebas de tamizaje del VIH en 1985-1987 ha dado lugar a una colaboración entre instituciones y programas para mejorar la inocuidad de la sangre donada en las Américas. Actualmente la seguridad de los productos hemáticos se logra mediante pruebas para la detección del virus de la hepatitis $C$ en un número cada vez mayor de países, así como con pruebas para la detección del VIH y de los agentes causales de la hepatitis B, la malaria, la sífilis y la enfermedad de Chagas. Sin embargo, los problemas que plantean la garantía de la calidad y la sostenibilidad aún no se resuelven en varias partes de América Latina.

\section{Perspectivas para el futuro}

La experiencia de tres años de trabajo en el marco del ONUSIDA ha puesto de manifiesto la complejidad de coordinar una respuesta verdaderamente intersectorial. Se han aprendido lecciones importantes que, si se aplican adecuadamente, contribuirán a fortalecer la capacidad nacional para hacer frente a este problema de salud que aumenta cada día. Los componentes de un buen programa son los siguientes:

- Un liderazgo nacional fuerte que guíe y module la respuesta nacional contra la infección por el $\mathrm{VIH} /$ sida;

- la capacidad de identificar y movilizar recursos, tanto internos como externos, para financiar las actividades de prevención y atención de la infec- 
ción por el VIH y las ITS sin desviar los recursos de otros programas esenciales;

- las alianzas múltiples y las alianzas políticas estratégicas, que deben incluir no solo a los asociados tradicionales, sino a todos los actores importantes que pueden y deben participar en la lucha contra el sida;

- la aplicación a gran escala de intervenciones técnica y científicamente sólidas (basadas en pruebas) que funcionen con efectividad en un contexto determinado;

- el conjunto de comportamientos preventivos eficaces y el respeto por los derechos humanos, en el contexto multicultural de los países americanos.

En los próximos años, la OPS seguirá proporcionando colaboración técnica en este campo a los Estados Miembros, contribuirá a fortalecer su autosuficiencia para abordar problemas prioritarios y promoverá la cooperación entre los países con un espíritu de verdadera equidad y panamericanismo.

\section{SYNOPSIS}

\section{AIDS and sexually transmitted infections in the Americas}

This document provides a brief review of the situation of HIV/aids and of sexually transmitted infections (STIs) in the Americas. Among the subjects covered are appropriate care models for HIV/aids, including access to antiretroviral drugs; preventing transmission from mother to child; im proved activities for preventing and controlling STIs; and interprogram activities to guarantee the safety of donated blood and blood products. 